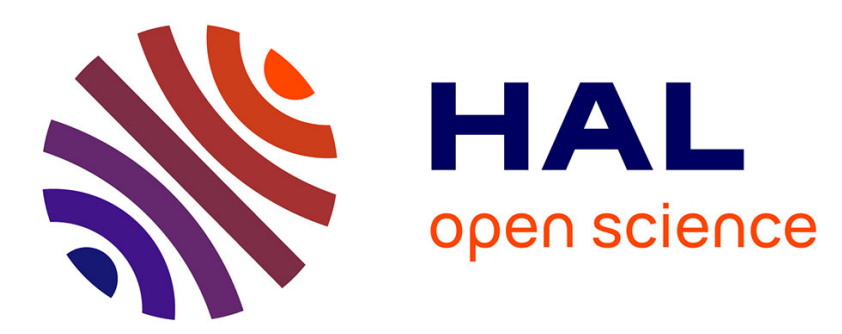

\title{
Orientation measurements of clay minerals by polarized attenuated total reflection infrared spectroscopy
}

\author{
Brian Gregoire, Baptiste Dazas, Fabien Hubert, Emmanuel Tertre, Eric \\ Ferrage, Laurent Grasset, Sabine Petit
}

\section{- To cite this version:}

Brian Gregoire, Baptiste Dazas, Fabien Hubert, Emmanuel Tertre, Eric Ferrage, et al.. Orientation measurements of clay minerals by polarized attenuated total reflection infrared spectroscopy. Journal of Colloid and Interface Science, 2020, 567, pp.274-284. 10.1016/j.jcis.2020.02.021 . hal-03000849

\section{HAL Id: hal-03000849 \\ https://hal.science/hal-03000849}

Submitted on 24 Nov 2020

HAL is a multi-disciplinary open access archive for the deposit and dissemination of scientific research documents, whether they are published or not. The documents may come from teaching and research institutions in France or abroad, or from public or private research centers.
L'archive ouverte pluridisciplinaire HAL, est destinée au dépôt et à la diffusion de documents scientifiques de niveau recherche, publiés ou non, émanant des établissements d'enseignement et de recherche français ou étrangers, des laboratoires publics ou privés. 
8 Institut de Chimie des Milieux et Matériaux de Poitiers, UMR 7285 CNRS-Université de Poitiers, 5 rue Albert Turpain, TSA 51106, 86073 Poitiers Cedex 9, France. 


\section{Abstract}

15 The orientation and organization of molecular guests within the interlayer of clay minerals

16 control the reactivity and performance of tailored organo-clay materials. Such a detailed 17 investigation of hybrid structure on the molecular scale is usually provided by computational 18 methods with limited experimental validation. In this study, polarized attenuated total reflection

19 infrared spectroscopy was used to extract quantitative orientation measurements of 20 montmorillonite particles. The validity of the evanescent electric field amplitude calculations 21 necessary to derive the order parameter was critically evaluated to propose a methodology for 22 determining the orientation of the normal to the clay layer relative to a reference axis, enabling 23 comparison with the results obtained from X-ray scattering experiments and molecular dynamic 24 simulations. Subsequently, the orientation of the interlayer water dipole and surface hydroxyls 25 with respect to the normal of the clay layer was experimentally determined, showing good 26 agreement with molecular simulations. This methodology may provide quantitative insights 27 into the molecular-level description of interfacial processes between organic molecules and clay 28 minerals.

\section{Keywords}

30 Attenuated total reflection spectroscopy; clay minerals; orientation; linear dichroism; thin layer 


\section{Introduction}

32 The increasing development of methods enabling fine tuning of the nanostructure of materials

33 at the molecular level has strongly contributed to the boost in nanotechnology. Beyond the 34 realm of graphene and its promising commercial potential, other 2D natural-based materials 35 have attracted considerable attention from the scientific community [1]. Owing to their naturally occurring nanoscale structures and associated large surface areas, clay minerals are subjected to increasing interest for numerous applications. For instance, the interactions of clay minerals with colloidal particles or molecular species result in interesting bulk-scale physical and chemical properties. Clay-based nanotechnology has thus led to promising innovation in nanoscience-related fields, such as materials science, electronics, food, and healthcare, contributing to the improvement of human quality of life [2-6]. Their abundance in nature, convenient preparation and biocompatibility are in part responsible for the large quantity of studies devoted to applications of clay minerals.

Sodium montmorillonite is certainly one of the most often used clay minerals owing to its low layer charge density, which is responsible for its swelling behavior and exfoliation properties. This material consists of a 2:1 layer composed of two tetrahedral sheets and one octahedral sheet. Isomorphous substitution of aluminum by magnesium in the octahedral sheet produces a negative charge that is counterbalanced by hydrated $\mathrm{Na}^{+}$cations located in the interlayer space [7]. The interlayer cations can be further exchanged by a variety of molecules or polymers, conferring the ability to finely tune the functionality of the composite [8-11]. The low charge density of the clay surface and its flat structure at the nanoscale level prevent aggregation of 
intercalated compounds and further enable molecular control of the molecule-molecule distance and orientation through a size matching effect [12]. This method opens the way for advanced reactivity, such as enantioselectivity and photonic properties. The performance of such materials is strongly dependent on the orientation of the guest molecules, which is sometimes difficult to assess. The molecular orientation is most often derived from the basal spacing obtained from X-ray diffraction (XRD) measurements in comparison with the size and shape of the guest molecules. In some cases, the interlayer domain is highly disordered, preventing local information from being directly obtained through XRD analyses [13]. Further complications arise when more than one single layer is examined when the orientation function of the clay particles has to be equally determined $[14,15]$. The preferred orientation of clay particles is of crucial importance, as it controls the geometric properties of the whole porous medium [16] and can vary from almost isotropic to perfectly oriented. The orientational distribution function of clay particles can be experimentally obtained through X-ray diffraction or X-ray microtomography measurements, but these techniques are insensitive to intercalated organic molecules. As a consequence, the interfacial interaction between organics and clay minerals remains inaccessible by these techniques. Vibrational spectroscopies are some of the few molecular-level probes that are inherently orientation sensitive and provide an alternative method for probing the organization of both clay particles and organic molecules in the same preparation [17]. Moreover, Fourier transform infrared (FTIR) spectroscopy allows the study of dynamic processes on a $10^{-14}-10^{-12} \mathrm{~s}$ time scale, which is attainable for molecular dynamic simulations. By explicitly taking into account the particle orientation, the experimental determination of molecular orientation with respect to a clay mineral surface, achievable by 
74 FTIR, spectroscopy opens a new way to validate or constrain MD simulations at the molecular 75 level.

76 The absorption of infrared light depends on the mutual orientation of the transition moment and 77 the electric field components. The polarization of infrared light enables the selection of the 78 orientation of the electric field and therefore offers additional control to measure the orientation of molecules and/or clay particles. The transition moments associated with minerals and organics are often well separated in frequency so that independent orientation measurements

81 can be carried out on the same sample. While the literature is rich in studies on molecular orientation determination, little focus has been placed on clay mineral orientation by FTIR spectroscopy. In a recent paper, the general methodology to extract the anisotropic optical constants of Na-montmorillonite by attenuated total reflectance infrared spectroscopy (ATRFTIR) was presented, and a strong out-of-plane transition moment associated with the Si-O stretching vibration was evidenced [18]. Therefore, such a Si-O stretching vibration band appears to be an adequate descriptor for the determination of the orientation of clay particles. In the few studies devoted to this objective, the authors systematically used thin-film approximation equations for the calculation of the electric field amplitude to derive the order parameter measuring the anisotropy of the clay deposit $[19,20]$. To further assess the validity of this approach, the matrix formalism for calculating the electric field amplitude proposed by

92 Hansen, considering the number of layers, the complex refractive index and the deposit 93 thickness, was used and compared with the approximate equations [21, 22]. 
94 This paper aims to investigate the ability to probe clay orientation by polarized ATR-FTIR

95 spectroscopy. To enable comparison with the results obtained by MD simulations or other experimental techniques, a methodology for determining the orientation of the normal to the phenomenon, the orientation of structural hydroxyls and water dipole moments of $\mathrm{Na}$ montmorillonite is experimentally determined and successfully compared to the MD results.

\section{Materials and Methods}

\section{II.1. Sample preparation}

SWy-3 montmorillonite clay was obtained from the Source Clays Repository of The Clay

103 Minerals Society. Clay with a size of $<1 \mu \mathrm{m}$ was collected by centrifugation and Na-saturated

104 using three saturation cycles in a $1 \mathrm{M} \mathrm{NaCl}$ solution. Excess salt was removed by dialysis until 105 the $\mathrm{Cl}^{-}$anion was no longer detected by the $\mathrm{AgNO}_{3}$ test.

\section{II.2. Polarized ATR-FTIR spectroscopy}

The ATR-FTIR spectra were recorded on a Nicolet IS50 equipped with a KBr beam splitter and

108 a DLaTGS detector. Polarized radiation was achieved by a ZnSe wire grid polarizer set before

109 the sample compartment. A VeeMax 3 accessory consisting of a thermally controlled horizontal

$11045^{\circ}$ single-bounce ATR plate was installed, and the temperature was set at a constant value of $11125^{\circ} \mathrm{C}$ for all experiments. A diluted clay suspension was pipetted and deposited on the Ge IRE 
112 (20 mm diameter), and the film was allowed to dry under ambient conditions. Polarized

113 reflectance spectra were acquired at a resolution of $4 \mathrm{~cm}^{-1}$, and 100 scans were coadded.

114 For vibrational bands that are not well resolved, such as the Si-O stretching vibration at 1085

$115 \mathrm{~cm}^{-1}$, band fittings of the region $600-1300 \mathrm{~cm}^{-1}$ were applied with a combination of Lorentzian

116 and Gaussian functions, as in Ras et al.[19] When band fitting was not necessary, the dichroism

117 ratio was calculated from the maximum intensity.

\section{II.3. Molecular Simulations}

119 The molecular structure of the montmorillonite sample was predicted using grand canonical

120 Monte Carlo (GCMC) and molecular dynamics (MD) simulations at selected hydration states

121 corresponding to the homogeneous one-layer hydrate $(1 \mathrm{~W})$ and the dehydrated state $(0 \mathrm{~W})$. The

122 system was composed of three clay sheets (with dimensions of 8-by-5 unit cells in the $a b$ plane)

123 and three interlayers. Isomorphic octahedral substitutions of $\mathrm{Al}^{3+}$ by $\mathrm{Mg}^{2+}$ were randomly

124 distributed in the clay structure to obtain the unit cell formula

125 inter $\left[\mathrm{Na}_{0.75}\right]^{\text {oct }}\left[\mathrm{Al}_{3.25} \mathrm{Mg}_{0.75}\right]^{\text {tet }}\left[\mathrm{Si}_{8.0}\right] \mathrm{O}_{20}(\mathrm{OH})_{4}$. The basal spacing was set according to the results

126 of montmorillonite determined by experimental X-ray diffraction modeling [13] of similar

127 samples. Accordingly, the Na-montmorillonite sample shows the least hydration heterogeneity

128 for one layer hydrated at a relative humidity $(\mathrm{RH})$ of 0.4 and under vacuum $(\sim 0 \mathrm{RH})$ conditions

129 for the dehydrated state. Consequently, the basal spacing for the present simulations was set, in

130 agreement with the former relative humidity, at $12.46 \AA$ and $9.75 \AA$ for the $1 \mathrm{~W}$ and $0 \mathrm{~W}$ states,

131 respectively. For both GCMC equilibrium and MD simulations, the following sets of

132 parameters were used. Interatomic interactions were modeled using the SPC/E water model and 
133 the CLAYFF model of silicate minerals [23]. The van der Waals "size" parameter of oxygen

134 atoms belonging to the clay layer was increased by $7 \%$ relative to the original CLAYFF model

135 as recommended [24]. Interatomic interactions were calculated in real space up to a distance of

$13615 \AA$ A. Beyond this distance, long-range Coulomb interactions were resolved by Ewald

137 summation. Ewald sum calculations were computed with a precision of $10^{-5}$.

138 The two systems were first equilibrated in the $\mu_{\mathrm{H} 2 \mathrm{O}} \mathrm{VT}$ ensemble (fixed volume, temperature,

139 and water chemical potential) in the GCMC simulation using a homemade program [24-29].

140 The one-layer hydrates were equilibrated using an RH of 0.4 at $298 \mathrm{~K}$. The target relative

141 humidity was converted to a water chemical potential using the ideal fluid relation $\mu_{\mathrm{H} 2 \mathrm{O}}=\mu^{0}{ }_{\mathrm{H} 2 \mathrm{O}}$

$142+k_{\mathrm{B}} T \ln (\mathrm{RH})$, where $\mu_{\mathrm{H} 2 \mathrm{O}}^{0}=k_{\mathrm{B}} T \ln \left(\Lambda^{3} \rho\right), \Lambda$ is the de Broglie wavelength of $\mathrm{H}_{2} \mathrm{O}(0.238376$

$143 \AA$ A), $k_{\mathrm{B}}$ is Boltzmann's constant, $T$ is the absolute temperature, and $\rho$ is the density of water

144 vapor at $298 \mathrm{~K}\left(7.7087481 \times 10^{-7}\right.$ molecules $\left.\AA^{-3}\right)$. Each GCMC simulation was carried out for

$1456 \times 10^{7}$ steps. At each step, one of the clay interlayers was selected randomly, and with an equal

146 probability, an attempt was made to remove a $\mathrm{H}_{2} \mathrm{O}$ molecule, add a $\mathrm{H}_{2} \mathrm{O}$ molecule in a random

147 configuration, or move a randomly chosen $\mathrm{Na}^{+}$ion or $\mathrm{H}_{2} \mathrm{O}$ molecule. Interlayer water quantities

148 were found to be 4.95 . This result is in agreement with previously reported water vapor

149 desorption isotherm experiments on similar samples [30]. For the dehydrated state, no water

150 molecule addition was attempted. Thus, at each step, one of the clay interlayers was selected

151 randomly, and an attempt was made to simply move a randomly chosen $\mathrm{Na}^{+}$ion.

152 Thermalized GCMC configurations were used as the starting points for the MD simulations.

153 Molecular dynamics simulations were performed with LAMMPS software [31]. Each 
154 simulation cell was first equilibrated in the NVE ensemble (fixed number of atoms, volume and 155 energy), weakly coupled to a Berendsen thermostat, for a total of 200000 steps at $T=298 \mathrm{~K}$.

156 During these steps, the timestep size for subsequent molecular dynamics simulations was

157 gradually increased from 0.001 to 0.5 femtoseconds to allow a smooth transition from GCMC

158 simulations performed with rigid clay layers to MD simulations with flexible layers. Finally,

159 each system was simulated for 1 nanosecond in the NVE ensemble and weakly coupled to a

160 Berendsen thermostat with a 0.5 fs timestep at $T=298 \mathrm{~K}$.

161 III. Order parameter and mean-squared electric field amplitude calculations

162

a)
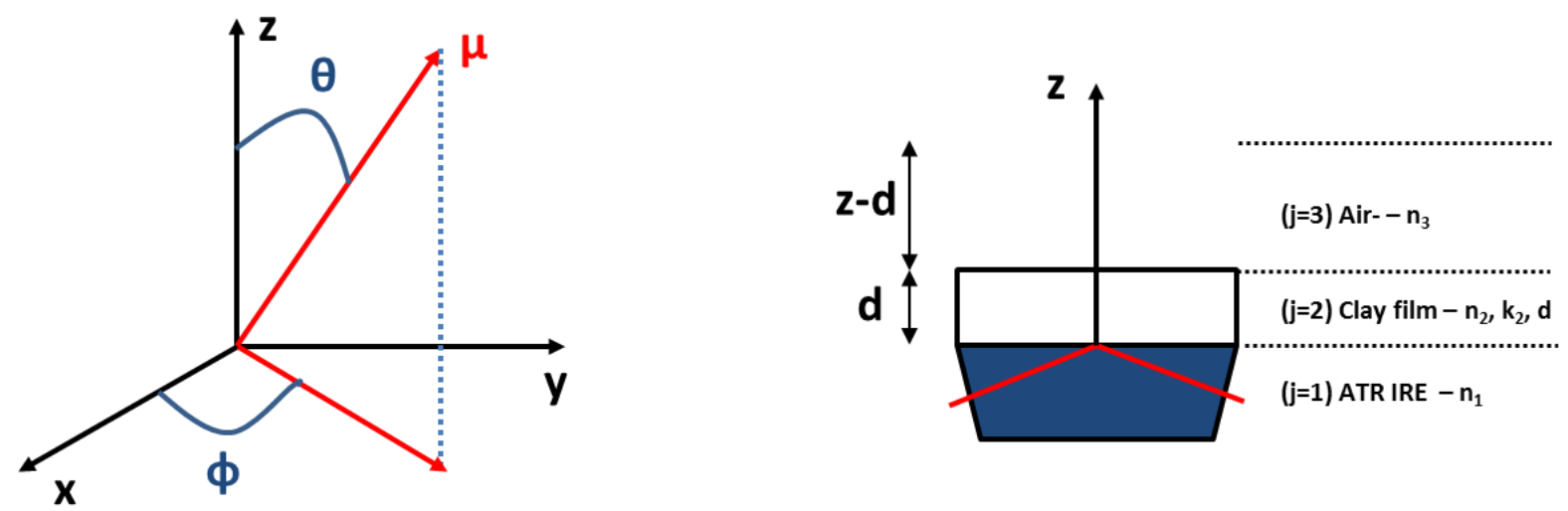

163

164 Figure 1. a) Definition of the laboratory (xyz) coordinate system used in this paper to define

165 the transition moments $\mu$ from the polar angles $\theta$ and $\varphi$. b) Optical configuration for stratified

166 layers with two interfaces (three-phase system). The notations are given in the text.

167 Polarized ATR-FTIR spectroscopy is commonly used to characterize dipole orientation or 168 molecular order given that the symmetry of the system is known. Recently, the uniaxial 
symmetry of Na-SWy-3 clays was verified, enabling the calculation of the anisotropic optical

170 constants [18]. For a beam propagating on the ATR crystal surface along the $\mathrm{x}$ direction, the

171 evanescent field is directed normal to this surface in the $\mathrm{z}$ direction. Using p-polarized radiation,

172 the evanescent electric field has components in the $\mathrm{x}$ and $\mathrm{z}$ directions, while for s-polarization,

173 it has components only in the y direction. Therefore, the mean-squared amplitude of the electric

174 field is separated into three orthogonal components:

$175<E^{2}>=<E_{x}^{2}>+<E_{y}^{2}>+<E_{z}^{2}>$

176 By using a projection similar to that for the electric field vector, $\mu$, the vector representing the

177 dipole change associated with a vibration, can be written as:

$178 \mu=\mu_{x}+\mu_{y}+\mu_{z}$

179 To calculate the absorption intensity, the individual dipoles must be summed:

$180 A=\sum_{i}\left|\mu_{i} \cdot E\right|^{2}$

181 Making use of the polar angle as presented in Figure 1a, the absorbance can be written as:

$A_{x}=k<\left(\mu . E_{x}\right)^{2}>=k<E_{x}^{2}>\sin ^{2}(\theta) \cos ^{2}(\phi)$

$183 A_{y}=k<\left(\mu . E_{y}\right)^{2}>=k<E_{y}^{2}>\sin ^{2}(\theta) \sin ^{2}(\phi)$

$184 A_{z}=k<\left(\mu . E_{z}\right)^{2}>=k<E_{z}^{2}>\cos ^{2}(\theta)$ 
185 For transition moments that are axially distributed around the $\mathrm{z}$ axis, as is the case for clays, all

186 values of $\varphi$ are equiprobable:

187

$$
<\cos ^{2}(\phi)>=<\sin ^{2}(\phi)>=\frac{1}{2}
$$

188 The dichroic ratio is obtained by dividing the p-polarized absorbance by the s-polarized

189 absorbance:

190

$R_{A T R}=\frac{A_{p}}{A_{s}}=\frac{A_{\chi}+A_{z}}{A_{y}}=\frac{<E_{\chi}^{2}>\sin ^{2}(\theta)+2<E_{Z}^{2}>\cos ^{2}(\theta)}{<E_{y}^{2}>\sin ^{2}(\theta)}$

191 For any orientations of the dipole defining an isotropic system, the isotropic dichroic ratio is

192 written as:

$193 R_{\text {iso }}=\frac{\left.\left\langle E_{x}^{2}\right\rangle+<E_{z}^{2}\right\rangle}{\left.<E_{y}^{2}\right\rangle}$

194 The order parameter S characterizing the degree of preferential orientation is calculated on the

195 basis of $2^{\text {nd }}$-order Legendre polynomials as:

$196 S=<P_{2} \cos (\theta)>=<\frac{3}{2} \cos ^{2}(\theta)-\frac{1}{2}>$

197 By substituting the angular factor in equation 8, the order parameter $\mathrm{S}$ is then defined as:

$198 S=\frac{\left\langle E_{x}^{2}>-R_{A T R}<E_{y}^{2}>+<E_{z}^{2}\right\rangle}{\left\langle E_{x}^{2}>-R_{A T R}<E_{y}^{2}>-2<E_{z}^{2}\right\rangle}$ 
The $S$ value can reach values from -0.5 to 1 . A value of -0.5 indicates that all transition moments

200 are precisely and uniformly oriented in the $\mathrm{x}$ or $\mathrm{y}$ direction, while a value of 1 indicates 201 transition moments along the $\mathrm{z}$ axis. Values of 0 are obtained for isotropic materials, where all 202 dipole moments have random orientation around the $\mathrm{z}$ axis or are all oriented at the magic angle $203\left(\theta=54.7^{\circ}\right)$.

204 The evaluation of the order parameter requires the calculation of the electric field $\left\langle\mathrm{E}^{2}\right\rangle$. The 205 general procedure for calculating the electric field amplitude at any point along a stratified 206 system was developed by Hansen [21]. Here, only the analytical expression will be given for a 207 3-phase system, as depicted in Figure 1b [32-34]. Because these expressions explicitly take 208 into account the thickness and absorption properties of the sample, they are called thickness209 and absorption-dependent equations:

$212<E_{y(j=2)}^{2}(z)>=\left|\left(1+r_{s}\right) \cos \left(\frac{2 \pi d \xi_{2}}{\lambda}\right)+i\left(\frac{\xi_{1}}{\xi_{2}}\right)\left(1-r_{s}\right) \sin \left(\frac{2 \pi d \xi_{2}}{\lambda}\right)\right|^{2}$

$213<E_{y(j=3)}^{2}(z)>=\left|t_{s}\right|^{2} \exp \left(\frac{-4 \pi \operatorname{Im}\left(\xi_{3}\right)}{\lambda}\right)(z-d)$

214

$$
<E_{x(j=1)}^{2}(z)>=\cos ^{2}(\alpha) \quad\left\{\left(1+R_{p}\right)-2 \sqrt{R_{p}} \cos \left(\delta^{p}-\frac{4 \pi d \xi_{1}}{\lambda}\right)\right\}
$$




$$
<E_{x(j=3)}^{2}(z)>=\left|\frac{\xi_{3}}{\hat{n}_{3}} t_{p}\right|^{2} \exp \left(\frac{-4 \pi \operatorname{Im}\left(\xi_{3}\right)}{\lambda}\right)(z-d)
$$

$$
<E_{z(j=2)}^{2}(z)>=\left|\frac{n_{1}^{2} \sin (\alpha)}{\hat{n}_{2}^{2}}\left(1-r_{p}\right) \cos \left(\frac{2 \pi d \xi_{2}}{\lambda}\right)+i\left(\frac{n_{1} \sin (\alpha)}{\xi_{2}}\right) \cos (\alpha)\left(1+r_{p}\right) \sin \left(\frac{2 \pi d \xi_{2}}{\lambda}\right)\right|^{2}
$$

$$
<E_{z(j=3)}^{2}(z)>=\left|\frac{n_{1} \sin (\alpha)}{\hat{n}_{3}} t_{p}\right|^{2} \exp \left(\frac{-4 \pi \operatorname{Im}\left(\xi_{3}\right)}{\lambda}\right)(z-d)
$$

223 where $\xi_{j}=\hat{n}_{j} \cos \left(\hat{\alpha}_{j}\right), \mathrm{j}$ is the layer taking a value from 1 to 3 for a 3 -phase system, $\hat{n}_{j}$ is the 224 isotropic complex optical constant $\left(\hat{n}_{j}=n_{j}+i \kappa_{j}\right), \alpha$ is the angle of incidence, Rs and Rp are 225 the reflectance signals, and rs, rp, ts and tp correspond to the Fresnel coefficients calculated 226 with the expressions given in [18].

227 Alternatively, Harrick proposed equations to calculate the amplitude of the electric field in the 228 second phase of a 3-phase system when the film thickness is very large compared to the 229 evanescent wave depth of penetration $[35,36]$. In this approximation, the film is neglected, and equations 11a-c are resolved at $\mathrm{z}=0$ for $\mathrm{d}=0$ and $\mathrm{n}_{2}=1$ (air). This corresponds to a 2-phase 
231 system, and therefore, these approximations are referred to as the 2-phase approximations. This

232 gives the following analytical expressions (equation 13a-c):

$233<E_{y(j=2)}^{2}(z=0)>=\frac{4 \cos ^{2}(\alpha)}{1-n_{21}^{2}}$

$234<E_{x(j=2)}^{2}(z=0)>=\frac{4 \cos ^{2}(\alpha)\left(\sin ^{2}(\alpha)-n_{21}^{2}\right)}{\left(1-n_{21}^{2}\right)\left[\left(1+n_{21}^{2}\right) \sin ^{2}(\alpha)-n_{21}^{2}\right]}$

$235<E_{z(j=2)}^{2}(z=0)>=\frac{4 \cos ^{2}(\alpha) \sin ^{2}(\alpha)}{\left(1-n_{21}^{2}\right)\left[\left(1+n_{21}^{2}\right) \sin ^{2}(\alpha)-n_{21}^{2}\right]}$

236 where $n_{21}=n_{2} / n_{1}$, with $n_{1}$ and $n_{2}$ being the real parts of the refractive indexes of phases 1 237 and 2, respectively.

238 In the other extreme case, where the film is very small compared to the penetration depth of the 239 evanescent wave, the electric field amplitude in the second phase can be calculated from 240 equations 11a-c at $\mathrm{z}=0$ by setting $\mathrm{d}=0$ and $\mathrm{n}_{2}=\mathrm{n}_{\text {film. }}$. In this approximation, the film is 241 optically considered but treated as non-absorbing $\left(\kappa_{2}=0\right)$, and the following analytical 242 equations are referred to as the thin-film approximation:

$243<E_{y(j=2)}^{2}(z=0)>=\frac{4 \cos ^{2}(\alpha)}{1-n_{31}^{2}}$

$244<E_{x(j=2)}^{2}(z=0)>=\frac{4 \cos ^{2}(\alpha)\left(\sin ^{2}(\alpha)-n_{31}^{2}\right)}{\left(1-n_{31}^{2}\right)\left[\left(1+n_{31}^{2}\right) \sin ^{2}(\alpha)-n_{31}^{2}\right]}$

$245<E_{z(j=2)}^{2}(z=0)>=\frac{4 n_{32}^{4} \cos ^{2}(\alpha) \sin ^{2}(\alpha)}{\left(1-n_{31}^{2}\right)\left[\left(1+n_{31}^{2}\right) \sin ^{2}(\alpha)-n_{31}^{2}\right]}$ 
where $n_{31}=n_{3} / n_{1}$ and $n_{32}=n_{3} / n_{2}$

\section{Results and Discussion}

\section{IV.1. Electric field propagation within a clay sample deposited on a Ge ATR crystal}

249 The availability of rigorous mathematical treatments for determining electric field propagation

250 through a sample enables a better understanding of the origin of ATR band intensity [21]. The 251 macroscopic treatment of the electric field considers interfaces between two media as a step

252 function of their respective dielectric constants [37-39]. Implicitly, the macroscopic physical 253 properties of a layer are assumed to be adequate descriptors of their microscopic properties, 254 irrespective of their dimensions or chemical/physical environments. As a consequence, 255 electromagnetic field theory accurately describes the electric field amplitude within a few angstroms from the surface. Although the expressions are mathematically exact, they are not exact in the sense of physics for describing the electric field amplitude within a film whose thickness is in the nanometer range. For this reason, it is not surprising to note that for similar systems, some authors may use the thin-film set of equations, while others prefer the 2-phase expressions [32, 40-45]. This illustrates well that profound differences exist in the way that authors use theory to interpret the molecular orientation of thin films. Interestingly, Citra and Axelsen, for example, demonstrate that contrary to expectations, the 2-phase approximation is more appropriate for describing a 25-50 ̊ thick layer of phospholipids [45]. Considering the 264 above arguments, it is surprising that very little attention has been paid to determining which 265 set of expressions is more appropriate and accurate for given experimental conditions. 
266 It is therefore of interest to evaluate the various theoretical treatments given above by carefully

267 examining the plausibility of the order parameter as obtained. More specifically, constraints 268 having the ability to dismiss a given approach if the results are irrelevant must be added. This 269 methodology offers advantages in understanding the origin of failures in theory. For example, 270 if the 2-phase system adequately describes the molecular orientation, it suggests that the optical 271 properties of the thin film are best ignored. Although questionable in terms of physics, it is 272 certainly more reasonable than systematically employing thin-film expressions when thin films 273 are deposited on an ATR crystal. This mismatch between theory and experiment originates from 274 the inherent difficulty of optically describing a thin film layer. Modifications of the dielectric 275 functions at the interface accounting for surface rugosity may substantially influence the electric 276 field amplitude within the thin film. Using an effective dielectric constant may partially solve 277 the problem, even if difficulties in experimentally determining this effective dielectric function 278 of a very thin layer still subsist [46]. Anderson and Hansen calculated the electric field 279 amplitude of an idealized single film composed of multiple anisotropic layers and showed that 280 optical constants may be chosen to reflect the physical behavior of the interface. This approach 281 assimilates optical constants not as a bulk phase optical property but rather as arbitrary fitting 282 parameters [47]. 
a)

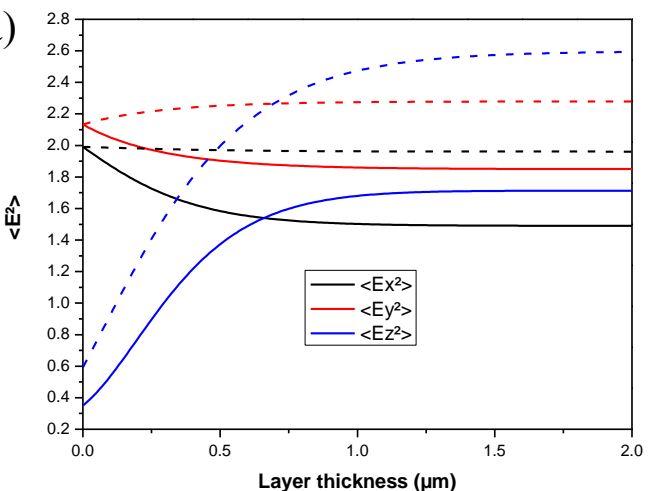

b)

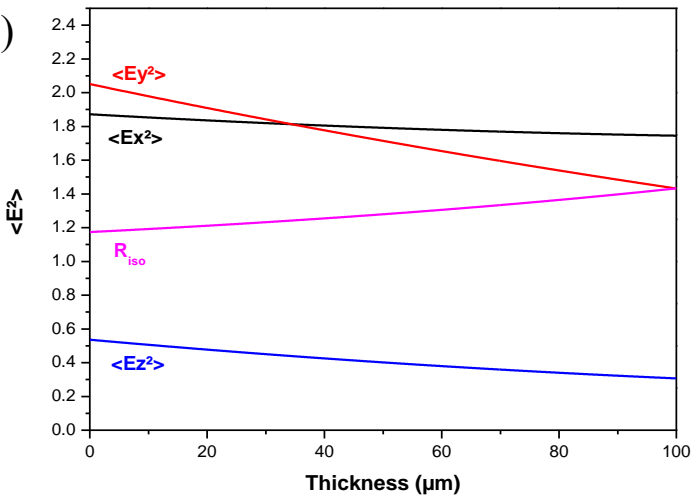

283

284

Figure 2. Orthogonal mean squared electric field amplitude a) at the interface between Ge IRE and a clay film as a function of the film thickness for absorbing (plain line) and non-absorbing (dashed line) films and b) along the thickness of a $100 \mathrm{~nm}$ thick film.

In Figure 2a, the electric field amplitudes along the $\mathrm{x}, \mathrm{y}$ and $\mathrm{z}$ axes were calculated using the thickness- and absorption-dependent equations for an isotropic 3-phase system (Ge IRE - Clay - Air; Figure 1b). The calculations were performed with an assumption of isotropic refractive indexes of 4 for Ge IRE, 1.4 for the clay film and 1 for air at $1085 \mathrm{~cm}^{-1}$ and an incidence angle of $45^{\circ}$. The three orthogonal components were computed at the interface between the ATR crystal and the clay film for different thicknesses of the clay film. The clay film was treated as a non-absorbing $(\mathrm{k}=0)$ and absorbing $(\mathrm{k}=0.7675)$ medium. Among the three orthogonal components of the electric field, $\left\langle\mathrm{Ez}^{2}\right\rangle$ exhibits the largest variation, with values ranging from 0.350 and 0.592 to 1.712 and 2.593 for a $2 \mu \mathrm{m}$ thick film for absorbing and non-absorbing media, respectively (Figure 2a). In the same thickness range, $\left\langle\mathrm{Ex}^{2}\right\rangle$ and $\left\langle\mathrm{Ey}^{2}\right\rangle$ show only a slight variation, which is more pronounced for absorbing media, where an overall decrease in the amplitude is observed compared to that in a non-absorbing medium. The thin-film and 2- 
phase approximations correspond to the amplitudes at which the thicknesses are 0 and $2 \mu \mathrm{m}$,

300 respectively, for the non-absorbing media. For the absorbing medium, these approximations 301 give values closer to the exact calculations for very thin films than for thick films. Difficulties

302 arise for intermediate film thicknesses of up to $1 \mu \mathrm{m}$, where the two approximate sets of 303 equations do not allow a reliable estimation of the electric field components. Therefore, 304 neglecting the imaginary part of the complex optical constants can induce significant variations 305 in the computation of electric field amplitude, leading to an erroneous determination of order 306 parameter $S$.

307 In Figure $\mathbf{2 b}$, the evolution of the electric field amplitude along the thickness for a $100 \mathrm{~nm}$ 308 thick film is shown. The electric field components are not constant within the film and decrease 309 almost linearly. The isotropic ratio, $\mathrm{R}_{\text {iso, }}$ increases when the film thickness increases, illustrating 310 the inherent uncertainty when the calculations are performed only at the interface between the 311 ATR crystal and the film. Therefore, the thinner the film is, the more accurate the determination 312 of the molecular orientation. Nevertheless, a mean value of the three orthogonal components of 313 the electric field within the film thickness is preferred to achieve more reliable results [44].

\section{5 film.}


a)

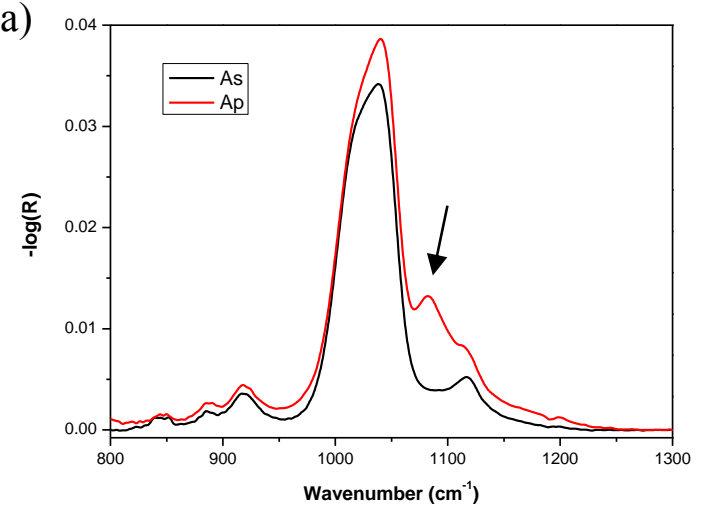

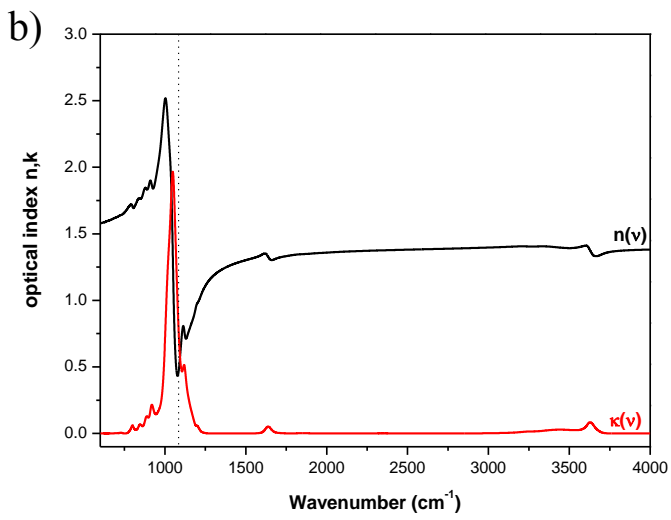

317 Figure 3. a) Experimental s- and p-polarized spectra of a $22 \mathrm{~nm}$ thick Na-SWy-3 film on Ge

318 IRE and b) isotropic optical constants, $\mathrm{n}(\mathrm{v})$ and $\kappa(\mathrm{v})$, of Na-SWy-3 from [18].

319 Figure 3a presents the ATR spectra of the $22 \mathrm{~nm}$ thick film analyzed with s-and p-polarization.

320 The most obvious change is the increase in the band located at $1085 \mathrm{~cm}^{-1}$ assigned to a

321 longitudinal mode with a transition moment oriented perpendicular to the film plane involving

322 stretching vibrations between $\mathrm{Si}$ and the apical oxygen of the tetrahedron, $\mathrm{Si}-\mathrm{O}_{\mathrm{ap}}$. Recalling 323 that the magnitude of light absorption depends on the mutual orientation of the vectors 324 associated with the transition moment and the electric field, the determination of the order 325 parameter provides insight into the orientation of the dipole moment with respect to the normal 326 to the interface. As a consequence, the determination of the orientation of the normal to the clay 327 film with respect to the $\mathrm{z}$ axis requires the determination of the orientation of the dipole moment 328 with respect to the normal to the clay layer. In the following, the transition moment associated 329 with the vibration at $1085 \mathrm{~cm}^{-1}$ is assumed to be colinear with the $\mathrm{Si}-\mathrm{O}_{\text {ap }}$ bond. This transition 330 moment is inclined by an angle $\delta$ with respect to the normal of the clay layer and isotropically 331 distributed around it. Furthermore, the normal to the clay layer forms an angle $\beta$ with the $\mathrm{z}$ axis 
332 and is isotropically distributed around it (Figure 4). The order parameter measured from the

333 ATR dichroic ratio can be expressed as a superposition of two uniaxial orientations according 334 to:

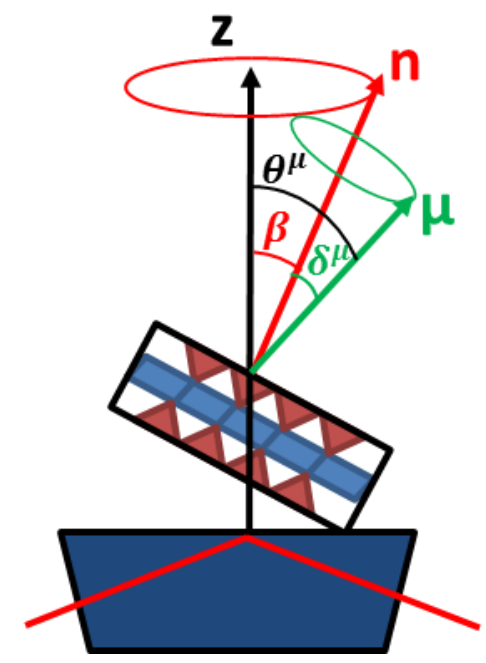

337 Figure 4. Geometric representation of the axially symmetric distribution of orientation of the 338 transition moment $\mu$ around the normal to the clay layer $n$ (angle $\delta$ ), which is distributed around 339 the reference direction, $\mathrm{z}$ (angle $\beta$ ). The distribution of the transition moment around the $\mathrm{z}$ axis 340 is characterized by the angle $\theta$

342 In the limit case where a single layer of smectite is deposited on the ATR crystal $\left(S_{\beta}\right.$ is assumed

343 to be equal to 1 ), equation 15 is reduced to $S_{\theta}^{S i O}=S_{\delta}^{S i O}$, offering the possibility to determine 
344 the angle between the transition moment under investigation and the normal to the clay surface.

345 Such an experiment can be achieved with the Langmuir-Blodgett technique, as performed by 346 Ras et al. [19] This film preparation technique generally leads to a higher degree of organization 347 than the layer-by-layer assembly (LbL) because in the former case, the film is formed at the 348 gas/liquid interface and offers additional control on the lateral distribution of clay mineral 349 particles $[19,48]$. Although previous experiments were performed on Na-SWy-1, we assumed 350 that the optical constants that were previously determined for Na-SWy-3 are valid [18]. The 351 dichroic ratio measured by these authors on a unique layer of Na-SWy-1 was found to be 8.33 352 using a ZnSe IRE. Based on the extraction of the isotropic optical constants from Figure $\mathbf{3 b}$ at $3531085 \mathrm{~cm}^{-1}\left(\mathrm{n}_{2}=0.467 ; \kappa_{2}=0.768\right)$, the mean square electric field amplitudes were calculated 354 using the different sets of equations presented in the theory section (Table 1a). For the three 355 sets of equations, similar results were obtained for the calculations of $\left\langle\mathrm{Ex}^{2}\right\rangle$ and $\left\langle\mathrm{Ey}^{2}\right\rangle$, 356 whereas important variations were noted for $\left\langle\mathrm{Ez}^{2}\right\rangle$. Given the very thin thickness of the sample, 357 the difference observed between the thin-film approximation and the thickness- and absorption358 dependent equations originates from the attenuation coefficient, which drastically reduced the $359<\mathrm{Ez}^{2}>$ value from 61.55 to 4.49 . This last value is close to that calculated with the 2-phase 360 approximation, where the film is not considered. The order parameter $S_{\theta}^{S i O}$, which is strongly 361 influenced by the value of $\left\langle\mathrm{Ez}^{2}\right\rangle$ according to equation 9, was also calculated, as shown in 362 Table 1a, along with the $\langle\theta\rangle$ value, assuming that $\left\langle\cos ^{2}(\theta)\right\rangle=\cos ^{2}(\langle\theta\rangle)$, which 363 holds only for a very narrow distribution of $\theta$. The value of $<\theta>$ calculated using the thin-film 364 approximations is irrelevant since it would signify that the transition moment is directed within 365 the plane of the clay layer. For the other equations used to compute the electric field amplitude, $366<\theta>$ values of $30^{\circ}$ and $35^{\circ}$ were obtained. In that case, the tilt angles appear to be very large, 
367 which would suggest large deformations of the tetrahedral units, which is contradictory to the

368 XRD analysis and molecular dynamics simulations [49-52]. Therefore, using the as-determined 369 optical indexes, none of the equations for the calculations of the mean square electric field 370 amplitudes is reliable. This suggests that the electromagnetic theory fails to properly describe 371 thin films of clay deposited on ATR crystals.

372 Table 1. Values of the three orthogonal mean square electric field amplitudes at $1085 \mathrm{~cm}^{-1}$ 373 calculated using the formalisms presented in the theory section, the order parameter of the 374 transition moment and the tilt angle.

\begin{tabular}{|c|c|c|c|c|c|}
\hline & $<E_{x}^{2}>$ & $<E_{y}^{2}>$ & $<E_{z}^{2}>$ & $S_{\theta}^{S i O}$ & $<\theta^{\text {SiO }}>^{d}$ \\
\hline \multicolumn{6}{|c|}{ a) Na-SWy- $\mathrm{n}_{1}=2.41 ; \mathrm{n}_{2}=0.467 ; \mathrm{R}_{\mathrm{ATR}}=8.33^{\mathrm{e}} ; \mathrm{v}=1085 \mathrm{~cm}^{-1}$} \\
\hline Thin Film ${ }^{a}-\kappa_{2}=0 ; d=0 n m$ & 1.914 & 2.416 & 61.547 & -0.307 & $69^{\circ}$ \\
\hline 2-phase approximation ${ }^{b}$ & 1.914 & 2.416 & 2.917 & 0.636 & $30^{\circ}$ \\
\hline \multicolumn{6}{|l|}{$k_{2}=0 ; d>d_{p}$} \\
\hline Thickness-Absorption dependent ${ }^{c}$ & 1.914 & 2.411 & 4.488 & 0.504 & $35^{\circ}$ \\
\hline \multicolumn{6}{|l|}{$\mathrm{K}_{2}=0.768 ; \mathrm{d}=1 \mathrm{~nm}$} \\
\hline \multicolumn{6}{|c|}{ b) Na-SWy $-\mathrm{n}_{1}=2.41 ; \mathrm{n}_{2}=1.40 ; \mathrm{R}_{\mathrm{ATR}}=8.33^{\mathrm{e}} ; \mathrm{v}=1085 \mathrm{~cm}^{-1}$} \\
\hline Thin Film $-k_{2}=0 ; d=0 \mathrm{~nm}$ & 1.914 & 2.416 & 0.759 & 0.885 & $16^{\circ}$ \\
\hline 2-phase approximation & 1.914 & 2.416 & 2.917 & 0.636 & $30^{\circ}$ \\
\hline \multicolumn{6}{|l|}{$K_{2}=0 ; d>d_{p}$} \\
\hline Thickness-Absorption dependent & 1.912 & 2.411 & 0.449 & 0.929 & $13^{\circ}$ \\
\hline \multicolumn{6}{|l|}{$\mathrm{K}_{2}=0.768 ; \mathrm{d}=1 \mathrm{~nm}$} \\
\hline \multicolumn{6}{|c|}{ c) $\mathrm{Na}-\mathrm{SWy}-\mathrm{n}_{1}=4 ; \mathrm{n}_{2}=1.40 ; \mathrm{R}_{\mathrm{ATR}}=4.10 ; \mathrm{v}=1085 \mathrm{~cm}^{-1}$} \\
\hline Thin Film $-k_{2}=0 ; d=0 \mathrm{~nm}$ & 1.991 & 2.133 & 0.592 & 0.776 & $23^{\circ}$ \\
\hline
\end{tabular}




\begin{tabular}{|llllll|}
\hline \hline 2-phase approximation & 1.991 & 2.133 & 2.276 & 0.396 & $39^{\circ}$ \\
$\qquad \mathrm{K}_{2}=0 ; d>d_{p}$ & & & & & $19^{\circ}$ \\
Thickness-Absorption dependent & 1.954 & 2.031 & 0.362 & 0.847 & \\
$\mathrm{~K}_{2}=0.768 ; d=22 \mathrm{~nm}$ & & & & & \\
\hline
\end{tabular}

a Assuming an infinite and non-absorbing thin film - see equation 14a-c

$\mathrm{b}$ The film is not considered - see equation 13a-c

c The electric field amplitude is averaged over the film thickness - see equation 11a-c

$\mathrm{d}$ Assuming an infinitely narrow orientational distribution $\left\langle\cos ^{2}(\boldsymbol{\theta})>=\cos ^{2}(<\theta>)\right.$

e $\mathrm{R}_{\mathrm{ATR}}$ taken from refs $[19,48]$. Note that the authors in these references expressed the dichroic ratio as Ap/As and was converted to be consistent with our definition - see equation 6 .

383 To overcome this difficulty, we analyzed the order parameter $S_{\delta}^{S i O}$ as a function of the isotropic

384 value of the refractive index of the clay film (Figure 5). The extinction coefficient, $\kappa(v)$, which

385 represents the dynamic dipole moment and describes the absorption of the electromagnetic

386 radiation, was set to $0.768[53,54]$. Although the values of $\left\langle\mathrm{Ex}^{2}\right\rangle$ and $\left\langle\mathrm{Ey}^{2}\right\rangle$ seem insensitive

387 to the refractive index, $\mathrm{n}_{2}$, drastic variation in $\left\langle\mathrm{Ez}^{2}\right\rangle$ is noted, which in turn affects the calculated

$388 S_{\delta}^{S i O}$ value. Changes in $S_{\delta}^{S i O}$ are the most important for the $\mathrm{n}_{2}$ value in the range of $0-1$ and

389 correspond to less than $2 \%$ of the variation per 0.1 unit of refractive index above $\mathrm{n}_{2}=1.4$. The

390 determination of the refractive index value is therefore of prime importance and strongly affects

391 the determination of the particle orientations. For these out-of-plane Si-O stretching vibrations,

392 values of $n_{2}$ between 0.61 and 1.15 have been reported for Na-SWy layers that lead to strongly

393 different order parameters [19, 20, 55]. 


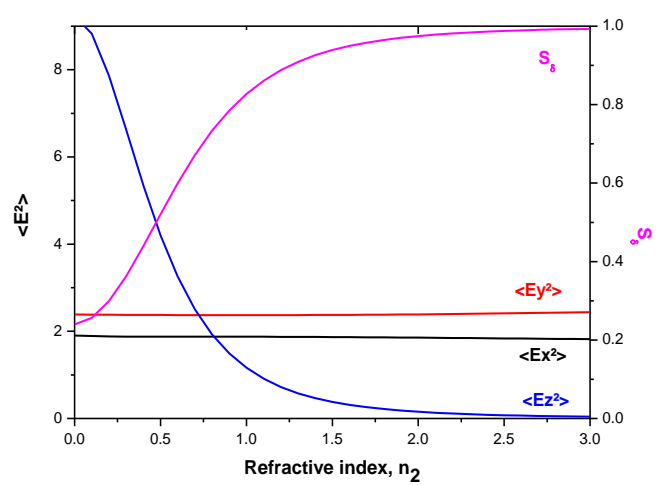

394

395 Figure 5. Evolution of the mean square electric field amplitude calculated with equation 11a-c 396 and the order parameter as a function of the refractive index of a Na-SWy-3 single layer $(\mathrm{d}=1$ $\mathrm{nm})$ on ZnSe IRE. The input parameters are $\mathrm{R}_{\mathrm{ATR}}=8.33, v=1085 \mathrm{~cm}^{-1}$ and $\kappa_{2}=0.768$.

398 To obtain more insight into the maximum value of $S_{\delta}^{\text {SiO }}$, MD simulations were performed on a 399 montmorillonite layer. The angle between the $\mathrm{Si}-\mathrm{O}$ apical bond and the normal to the clay layer 400 was extracted and averaged over a simulation period of 125 fs. Subsequently, the distribution 401 function $f(\delta)$ was extracted, and the $S_{\delta}^{\text {SiO }}(M D)$ value was calculated according to:

$402 S_{\delta}^{\text {SiO }}=<P_{2} \cos (\delta)>=<\frac{3}{2} \cos ^{2}(\delta)-\frac{1}{2}>$

403 The $S_{\delta}^{\text {SiO }}(M D)$ value obtained was 0.987 , corresponding to a $<\delta>$ value of $5.33^{\circ}$. Reporting this 404 value in Figure 5 enables determination of a refractive index value of 2.4. Since this value is 405 extracted on the basis of structural considerations from molecular simulations, it has to be 406 regarded as the maximum value relating the transition moment to the normal of the clays. 407 Submicron natural clay minerals may present structural faults and layer flexibility, leading to a 
more disordered structure that would in turn decrease the experimental $S_{\delta}^{\text {SiO }}$ value $[56,57]$. Due to the inherent difficulty in precisely determining this value and given the low intensity of the $1085 \mathrm{~cm}^{-1}$ ATR band, an arbitrary value of refractive index of 1.4 will be used, resulting in an $S_{\delta}^{\text {SiO }}$ value of 0.929 (Table 1b). This corresponds to the refractive index in a region where there is no absorption in Figure 3b and may indicate that the experimental value of 0.467 for $\mathrm{n}_{2}$ is decreased substantially by the strong anomalous dispersion associated with the very intense SiO stretching vibration at $1039 \mathrm{~cm}^{-1}$.

\section{IV.4. Experimental determination of $S_{\beta}$ for thin film deposits}

For the $22 \mathrm{~nm}$ thick Na-SWy-3 deposit on the Ge IRE, an experimental dichroic ratio of 4.1 was measured. Using the newly determined value of the refractive index, the electric field amplitudes were calculated with the approximate and exact equations (Table 1c). Both thinfilm approximations and thickness- and absorption-dependent equations give similar $S_{\theta}^{\text {SiO }}$ values of 0.776 and 0.847 , respectively, while a value of 0.396 was obtained using the 2-phase approximations. This suggests that the optical properties of the clay film have to be taken into account for reliable calculation of the electric field amplitude. Using equation $\mathbf{1 5}$ and the calculated value of $S_{\delta}^{\text {SiO }}(0.929)$, the order parameter representing the orientation of the normal to the clay film with respect to the $\mathrm{z}$ axis, $S_{\beta}$, is 0.912 , corresponding to a $<\beta>$ value of $14^{\circ}$. In a recent publication, measurements of the order parameters of a dozen-micrometer-thick NaSWy-2 film led to an experimental $S_{\beta}$ value of approximately 0.65 [58]. For thinner sample preparation, as used for FTIR spectroscopy measurements, a higher $S_{\beta}$ value would be expected, accounting for the lower number of layers investigated and their less disordered 
a)

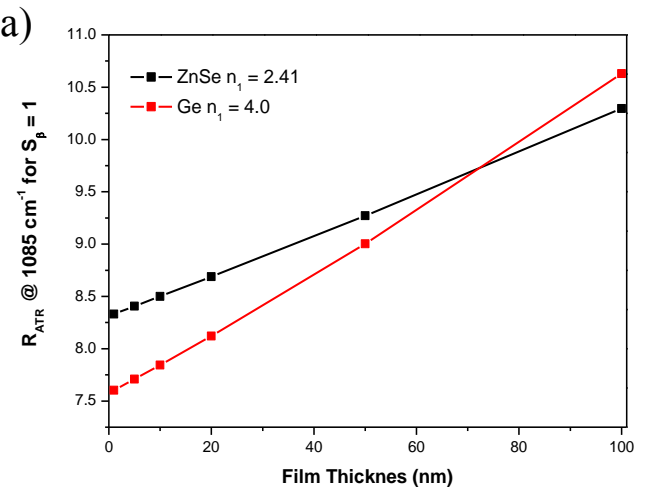

b)

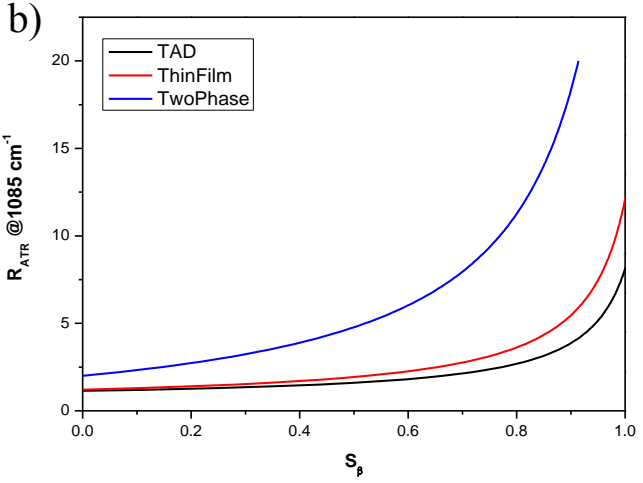

431

432

433

434

435

Figure 6. a) Evolution of the dichroic ratio for different film thicknesses in the case of perfectly oriented Na-SWy-3 clay $\left(S_{\beta}=1\right)$ and $b$ ) expected dichroic ratio for various values of $S_{\beta}$ obtained through the three sets of electric field amplitude calculations for a $20 \mathrm{~nm}$ thick film on Ge IRE. The input parameters are $v=1085 \mathrm{~cm}^{-1}, \mathrm{n}_{1}=4, \mathrm{n}_{2}=1.4$ and $\kappa_{2}=0.768$.

Figure 6a presents the variation in the dichroic ratio as a function of the sample thickness for the $1085 \mathrm{~cm}^{-1}$ band and considering $S_{\beta}=1$. The nature of the ATR IRE element dictates the value of the dichroic ratio as measured irrespective of the particle organization. Upon variation of the sample thickness, a sharper increase is observed with the Ge IRE than with the ZnSe or diamond IRE. Therefore, reliable orientation measurements require the precise determination of the sample thickness. As a consequence, a comparison of the dichroic ratio can be performed only with similar IRE elements. Figure $\mathbf{6 b}$ presents the influence of $S_{\beta}$ on the dichroic ratio measured on the $22 \mathrm{~nm}$ film with a Ge IRE using different formalisms for the calculations of the electric field. Regarding the results obtained from the thickness- and absorption-dependent 
equations, the variation in the dichroic ratio for $S_{\beta}$ below 0.6 is very limited. This suggests that

446 precise orientation measurements of nearly isotropic clay particles may not be achievable using

447 ATR spectroscopy. In this case, other transition moments should be considered. Figure $6 \mathbf{b}$ also

448 suggests the need to determine the dichroic ratio with the best accuracy. The highest precision

449 of the orientation measurement was achieved for $S_{\beta}$ greater than 0.6 , where large variations in

450 the dichroic ratio were correlated to small variations in the clay orientation. It can thus be

451 concluded that the orientation of an anisotropic clay particle organization can readily be

452 determined using ATR-FTIR spectroscopy according to the methodology proposed here.

453 Moreover, using the approximate equations instead of the most complete equations may

454 underestimate the $S_{\beta}$ value. Future directions for this work could be the experimental 455 determination of the orientation of all transition moments of clays with respect to the clay 456 normal, but the validity of the assumptions for the electric field calculations still need to be 457 proven.

IV.5. Determination of structural hydroxyl and interlayer water orientations with respect to the clay layer surface.

460 The benefit of ATR-FTIR spectroscopy lies in its high sensitivity for probing interfacial 461 phenomena. For a more accurate description of the organization of organic molecules on 462 mineral surfaces, from the nanometer to the micrometer scales, the mineral organization must 463 be taken into account. This is illustrated in this section, where the orientations of structural 464 hydroxyls and water molecules are determined with respect to the clay mineral surface, which 465 allows comparison with the MD results. 
To improve the signal-to-noise ratio, spectra were calculated from the anisotropic optical 467 constants determined on a thick deposit of Na-SWy-3 (>2 $\mu \mathrm{m})$. Subsequently, s- and p468 polarized ATR spectra were computed assuming a $1 \mathrm{~nm}$ thin film, where the information about 469 the orientation of all transition moments corresponds to that of the bulk deposit. This procedure 470 guarantees a high-quality spectrum with an improved signal-to-noise ratio. The normal to the 471 clay orientation with respect to the $\mathrm{z}$ axis was determined from the $\mathrm{Si}-\mathrm{O}$ stretching vibration 472 dichroic ratio at $1085 \mathrm{~cm}^{-1}$ according to the method described in this paper. The clay mineral hydroxyl orientation was determined from their stretching vibrations at $3630 \mathrm{~cm}^{-1}$. Due to the strong overlap between the vibrations of hydroxyl groups and those of water, the same thick 475 deposit was dehydrated under an air-dried stream for $24 \mathrm{~h}$, and the dehydrated-clay optical 476 constants were extracted for the simulation of polarized ATR spectra. Using dehydrated or 477 monohydrated samples was not observed to significantly affect the experimental dichroic ratio 478 of the Si-O stretching bands, so the orientation of the particles remained equivalent for both 479 hydration states, in agreement with the MD simulations. For water molecules, the dichroic ratio 480 from the bending motion at $1637 \mathrm{~cm}^{-1}$ was calculated. For both transition moments, the uniaxial 481 orientation of the transition moment was determined with respect to the $\mathrm{z}$ axis $\left(S_{\theta}^{O H}\right)$. To discard 482 the influence of particle orientations, an order parameter relative to the normal to the clay, $S_{\delta}^{O H}$, 483 was obtained according to:

$484 S_{\delta}^{\mathrm{OH} \text { or } \mathrm{H}_{2} \mathrm{O}}=\frac{S_{\theta}^{\mathrm{OH} \text { or } \mathrm{H}_{2} \mathrm{O}}}{S_{\beta}}$

485 where $S_{\beta}$ is determined using equation 15. The dichroic ratio of the $\mathrm{SiO}$ stretching vibrations 486 extracted from the simulated s- and p-polarized spectra was found to be 2.77 , corresponding to 
a $S_{\beta}$ value of 0.847 . This value is lower than that measured for a $22 \mathrm{~nm}$ thick sample $\left(S_{\beta}=\right.$ 0.912), suggesting slightly less anisotropic particle organization for thicker deposits (Table 2a). Using the isotropic optical constants from Figure $\mathbf{3 b}$ at the wavenumbers of the two transition moments, i.e., $3630 \mathrm{~cm}^{-1}$ and $1638 \mathrm{~cm}^{-1}$ for $v_{\mathrm{MO}-\mathrm{H}}$ and $\delta_{\mathrm{HOH}}$, respectively, and the experimentally determined dichroic ratio, the order parameter $S_{\theta}^{O H}$ was calculated according to equation 9 and converted to $S_{\delta}^{O H}$ using equation 17. MD simulations were comparatively performed, and the angular distributions of the transition moments were extracted and are reported in Table 2b-c. The structural hydroxyls give an experimental $S_{\delta}^{O H}$ value of -0.421 , which is very close to that determined by MD simulations $(-0.436)$, confirming that the hydroxyls are oriented nearly parallel to the layer, as expected for dioctahedral smectites. The good agreement between the experimental and expected $S_{\delta}^{O H}$ values fully supports the methodology presented in this work for extracting $S_{\beta}$ and therefore validates the proposed values of the optical constants, $\mathrm{n}_{2}$ and $\kappa_{2}$, to determine clay mineral orientation. The dichroism ratio determined from the bending vibrations of the water molecules was 1.23 , corresponding to an $S_{\delta}^{\mathrm{H}_{2} \mathrm{O}}$ of -0.053 . This value indicates that the orientation of the water molecules is nearly isotropic. The MD-extracted value is slightly lower than the experimental value, reflecting a higher proportion of water molecules with their dynamic transition moments perpendicular to

504 the z-axis. This slight discrepancy may originate from the contribution of surface-adsorbed 505 water molecules and/or 2W layers, as commonly observed at ambient humidity and not taken 506 into account in the simulations. [13, 30, 59]. On the basis of the MD simulations, Szczerba et al. showed that $2 \mathrm{~W}$ montmorillonite layers contain a higher proportion of bidentate water 
molecules whose transition moments are parallel to the $\mathrm{z}$ axis, contributing to an increase in the $509 S_{\delta}^{\mathrm{H}_{2} \mathrm{O}}$ value [60].

510 Table 2: Determination of the order parameters $\boldsymbol{S}_{\boldsymbol{\beta}}, \boldsymbol{S}_{\boldsymbol{\theta}}^{\boldsymbol{\mu}}$ and $\boldsymbol{S}_{\boldsymbol{\delta}}^{\boldsymbol{\mu}}$ using the thickness- and 511 absorption-dependent equations and comparison with the MD results

\begin{tabular}{|c|c|c|c|c|c|}
\hline & $S_{\beta}$ & $\overline{S_{\theta}^{O H}}$ & $\begin{array}{c}S_{\delta}^{O H} \\
\text { or } \\
S_{\delta}^{\mathrm{H}_{2} \mathrm{O}}\end{array}$ & $\begin{array}{c}<\delta^{O H}> \\
\text { or } \\
<\delta^{H_{2} O}>\end{array}$ & $\begin{array}{c}S_{\delta}^{O H} \text { or } S_{\delta}^{H_{2} O} \\
\text { from MD }\end{array}$ \\
\hline \multicolumn{6}{|c|}{ a) $v_{\text {SiO }}-n_{1}=4 ; n_{2}=1.4 ; K_{2}=0.768 ; R_{\text {ATR }}=2.77 ; v=1085 \mathrm{~cm}^{-1} ; d=1 \mathrm{~nm}$} \\
\hline Thickness-Absorption dependent & 0.847 & $\mathrm{x}$ & $\mathrm{x}$ & $\mathrm{x}$ & $\mathrm{x}$ \\
\hline \multicolumn{6}{|c|}{ b) $v_{\text {MO-H }}-n_{1}=4 ; n_{2}=1.388 ; k_{2}=0.033 ; R_{A T R}=1.01 ; v=3630 \mathrm{~cm}^{-1} ; d=1 \mathrm{~nm}$} \\
\hline Thickness-Absorption dependent & 0.847 & -0.356 & -0.421 & $77^{\circ}$ & {$[-0.437 ;-0.367]^{\mathrm{a}}$} \\
\hline \multicolumn{6}{|c|}{ c) $\delta_{\text {оно }}-n_{1}=4 ; n_{2}=1.330 ; k_{2}=0.048 ; R_{A T R}=1.23 ; v=1638 \mathrm{~cm}^{-1} ; d=1 \mathrm{~nm}$} \\
\hline Thickness-Absorption dependent & 0.847 & -0.045 & -0.053 & $57^{\circ}$ & {$[-0.213 ;-0.140]^{a}$} \\
\hline
\end{tabular}

513 a Extremum values from MD simulation assuming rigid or flexible clay

\section{Concluding remarks and perspectives}

516 The present study provides the general methodology for determining clay particle orientation

517 using polarized ATR-FTIR spectroscopy and allows the derivation of three major conclusions.

518 First, $\mathrm{Si}-\mathrm{O}_{\text {ap }}$ transition moments are suitable for determining clay particle orientations of rather

519 anisotropic organizations $(\mathrm{S}>0.6)$. The appropriate optical constants associated to the $\mathrm{Si}-\mathrm{O}_{\mathrm{ap}}$

520 vibration for reliable measurements of particle orientations were determined: the frequency

521 dependence variation of the refractive index is best ignored ( $\mathrm{n}_{2}$ set to 1.4$)$, and the extinction 
coefficient was determined by pATR measurements to be $\kappa_{2}=0.768$. Second, by comparison with the absorption- and thickness-dependent equations, the thin-film approximations often used in literature $[19,61]$ were observed to slightly underestimate the order parameter, while the 2-phase approximation yielded unreliable results. Third, as a proof of concept in the present study, structural hydroxyl and water molecule orientations were experimentally determined on Na-SWy-3 smectite with respect to the normal of the clay using equation 15 with an $S_{\delta}^{S i O}$ value of 0.929 (which depends on the ATR IRE and the clay mineral studied) to extract $S_{\beta}$ and equation 17 to determine $S_{\delta}^{\mathrm{OH} \text { or } \mathrm{H}_{2} \mathrm{O}}$. This result was found to be in fairly good agreement with the results of molecular dynamics simulations.

The present work extends the quantitative treatment of clay minerals using pATR methods to include sample thicknesses larger than a single monolayer of particles [19, 48, 61]. This upper scale, which could be referred as to the aggregate scale, is of particular importance for enabling connection between the orientation of particles and the macroscopic properties of hybrid or composite materials. Taking advantage of a reference function describing the orientation of clay particles [62], the order parameter as obtained from pATR measurements using the presented methodology is thus sufficient to determine the full shape of the orientation distribution function. Such an information is a key parameter for the design of clay-based engineered materials with tunable properties [63-66]. In addition to the refined analysis of clay particles orientation by pATR measurements, the logical perspective of this work is to follow up this study with orientation determination of organic molecules adsorbed on or intercalated within clay particles. Because of the great sensitivity of FTIR spectroscopy to organic functional groups, such investigation should help to identify how organic molecules interact with clay 
544 interfaces. This is of particular importance given the prominent role played by organo-clays in

545 various applications.

\section{Acknowledgments}

547 The CNRS interdisciplinary "défi Needs", through its "MiPor" program (Project

548 TRANSREAC), is acknowledged for providing financial support for this study. The authors

549 acknowledge financial support from the European Union (ERDF) and "Région Nouvelle 550 Aquitaine". 
[1] W. Wang, A. Wang, Nanoscale Clay Minerals for Functional Ecomaterials: Fabrication, Applications, and Future Trends, in: L.M.T. Martínez, O.V. Kharissova, B.I. Kharisov (Eds.), Handbook of Ecomaterials, Springer International Publishing, Cham, 2019, pp. 2409-2490. https://doi.org/10.1007/978-3-319-68255-6_125.

[2] M.I. Carretero, Clay minerals and their beneficial effects upon human health. A review, Applied Clay Science 21(3) (2002) 155-163. https://doi.org/10.1016/S0169-1317(01)00085-0. [3] C.H. Zhou, An overview on strategies towards clay-based designer catalysts for green and sustainable catalysis, Applied Clay Science 53(2) (2011) 87-96. https://doi.org/10.1016/j.clay.2011.04.016.

[4] S.-J. Choi, Y.-R. Kim, Bioinspired Layered Nanoclays for Nutraceutical Delivery System, Advances in Applied Nanotechnology for Agriculture, American Chemical Society2013, pp. 207-220. https://doi.org/10.1021/bk-2013-1143.ch012.

[5] J. Ma, Q. Liu, L. Zhu, J. Zou, K. Wang, M. Yang, S. Komarneni, Visible light photocatalytic activity enhancement of $\mathrm{Ag} 3 \mathrm{PO} 4$ dispersed on exfoliated bentonite for degradation of rhodamine B, Applied Catalysis B: Environmental $182 \quad$ (2016) 26-32. https://doi.org/10.1016/j.apcatb.2015.09.004.

[6] M. Ogawa, K. Kuroda, Photofunctions of Intercalation Compounds, Chemical Reviews 95(2) (1995) 399-438. https://doi.org/10.1021/cr00034a005.

[7] M.F. Brigatti, E. Galán, B.K.G. Theng, Chapter 2 - Structure and Mineralogy of Clay Minerals, in: F. Bergaya, G. Lagaly (Eds.), Developments in Clay Science, Elsevier2013, pp. 21-81. https://doi.org/10.1016/B978-0-08-098258-8.00002-X.

[8] M. Darder, M. López-Blanco, P. Aranda, F. Leroux, E. Ruiz-Hitzky, Bio-Nanocomposites Based on Layered Double Hydroxides, Chem. Mater. 17(8) (2005) 1969-1977. https://doi.org/10.1021/cm0483240.

[9] B. Wicklein, M. Darder, P. Aranda, E. Ruiz-Hitzky, Bio-organoclays based on phospholipids as immobilization hosts for biological species, Langmuir 26(7) (2010) 5217 5225. https://doi.org/10.1021/la9036925.

[10] J.W. Jordan, Organophilic Bentonites. I. Swelling in Organic Liquids, The Journal of Physical and Colloid Chemistry 53(2) (1949) 294-306. https://doi.org/10.1021/j150467a009.

[11] A. Yamagishi, M. Soma, Optical resolution of metal chelates by use of adsorption on a colloidal clay, Journal of the American Chemical Society 103(15) (1981) 4640-4642. https://doi.org/10.1021/ja00405a086.

[12] M. Eguchi, T. Shimada, D.A. Tryk, H. Inoue, S. Takagi, Role of Hydrophobic Interaction in Controlling the Orientation of Dicationic Porphyrins on Solid Surfaces, The Journal of Physical Chemistry C 117(18) (2013) 9245-9251. https://doi.org/10.1021/jp400645d.

[13] E. Ferrage, B. Lanson, B.A. Sakharov, V.A. Drits, Investigation of smectite hydration properties by modeling experimental X-ray diffraction patterns: Part I. Montmorillonite hydration properties, American Mineralogist 90(8-9) (2005) 1358. https://doi.org/10.2138/am.2005.1776.

[14] F. Hubert, D. Prêt, E. Tertre, E. Ferrage, B. Nauleau, I. Bihannic, M. Pelletier, B. Demé, Investigating the anisotropic features of particle orientation in synthetic swelling clay porous 
media, Clays and Clay Minerals

$61(5)$

(2013)

$397-415$.

595 https://doi.org/10.1346/ccmn.2013.0610501.

596 [15] E. Ferrage, F. Hubert, A. Baronnet, O. Grauby, E. Tertre, A. Delville, I. Bihannic, D. Pret, L.J. Michot, P. Levitz, Influence of crystal structure defects on the small-angle neutron scattering/diffraction patterns of clay-rich porous media, Journal of Applied Crystallography 51(5) (2018) 1311-1322. https://doi.org/10.1107/S160057671801052X.

600

601

602

603

604

605

606

607

608

609

610

611

612

613

614

615

616

617

[16] T. Dabat, A. Mazurier, F. Hubert, E. Tertre, B. Grégoire, B. Dazas, E. Ferrage, Mesoscale Anisotropy in Porous Media Made of Clay Minerals. A Numerical Study Constrained by Experimental Data, Materials 11(10) (2018). https://doi.org/10.3390/ma11101972.

[17] R. Ikeda, B. Chase, N.J. Everall, Basics of Orientation Measurements in Infrared and Raman Spectroscopy, in: M. Chalmers, P.R. Griffiths (Eds.), Handbook of Vibrational Spectroscopy2001. https://doi.org/10.1002/9780470027325.s0501m.pub2.

[18] B. Grégoire, B. Dazas, M. Leloup, F. Hubert, E. Tertre, E. Ferrage, S. Petit, Optical theory based simulation of Attenuated Total Reflection infrared spectra of Montmorillonite, Submitted to Clays and Clay Minerals (2019).

[19] R.H.A. Ras, C.T. Johnston, E.I. Franses, R. Ramaekers, G. Maes, P. Foubert, F.C. De Schryver, R.A. Schoonheydt, Polarized Infrared Study of Hybrid Langmuir-Blodgett Monolayers Containing Clay Mineral Nanoparticles, Langmuir 19(10) (2003) 4295-4302. https://doi.org/10.1021/la026786r.

[20] A. Holmgren, X. Yang, A Polarized Fourier Transform Infrared Spectrometry Attenuated Total Reflection Study of Bentonite Settled onto Magnetite, The Journal of Physical Chemistry C 112(42) (2008) 16609-16615. https://doi.org/10.1021/jp8048923.

[21] W.N. Hansen, Electric Fields Produced by the Propagation of Plane Coherent

618

619

620

621

622

623

624

625

626

627

628

629

630

631

632

633

634

635

636

637
Electromagnetic Radiation in a Stratified Medium, J. Opt. Soc. Am. 58(3) (1968) 380-390. https://doi.org/10.1364/josa.58.000380.

[22] W.N. Hansen, Expanded formulas for attenuated total reflection and the derivation of absorption rules for single and multiple ATR spectrometer cells, Spectrochimica Acta 21(4) (1965) 815-833. https://doi.org/10.1016/0371-1951(65)80039-X.

[23] R.T. Cygan, J.-J. Liang, A.G. Kalinichev, Molecular Models of Hydroxide, Oxyhydroxide, and Clay Phases and the Development of a General Force Field, J. Phys. Chem. B 108(4) (2004) 1255-1266. https://doi.org/10.1021/jp0363287.

[24] E. Ferrage, B.A. Sakharov, L.J. Michot, A. Delville, A. Bauer, B. Lanson, S. Grangeon, G. Frapper, M. Jiménez-Ruiz, G.J. Cuello, Hydration Properties and Interlayer Organization of Water and Ions in Synthetic Na-Smectite with Tetrahedral Layer Charge. Part 2. Toward a Precise Coupling between Molecular Simulations and Diffraction Data, The Journal of Physical Chemistry C 115(5) (2011) 1867-1881. https://doi.org/10.1021/jp105128r.

[25] A. Delville, Modeling the clay-water interface, Langmuir 7(3) (1991) 547-555. https://doi.org/10.1021/la00051a022.

[26] E. Rinnert, C. Carteret, B. Humbert, G. Fragneto-Cusani, J.D.F. Ramsay, A. Delville, J.L. Robert, I. Bihannic, M. Pelletier, L.J. Michot, Hydration of a Synthetic Clay with Tetrahedral Charges: A Multidisciplinary Experimental and Numerical Study, The Journal of Physical Chemistry B 109(49) (2005) 23745-23759. https://doi.org/10.1021/jp050957u.

[27] P. Porion, A.M. Faugère, A. Delville, 1H and 7Li NMR Pulsed Gradient Spin Echo Measurements and Multiscale Modeling of the Water and Ionic Mobility within Aqueous 
Dispersions of Charged Anisotropic Nanoparticles, The Journal of Physical Chemistry C 639 112(31) (2008) 11893-11900. https://doi.org/10.1021/jp802928n.

640 [28] P. Porion, L.J. Michot, A.M. Faugère, A. Delville, Structural and Dynamical Properties of 641 the Water Molecules Confined in Dense Clay Sediments: a Study Combining 2H NMR 642 Spectroscopy and Multiscale Numerical Modeling, The Journal of Physical Chemistry C 643 111(14) (2007) 5441-5453. https://doi.org/10.1021/jp067907p.

644 [29] M. Jiménez-Ruiz, E. Ferrage, A. Delville, L.J. Michot, Anisotropy on the Collective 645 646 Dynamics of Water Confined in Swelling Clay Minerals, The Journal of Physical Chemistry A 116(10) (2012) 2379-2387. https://doi.org/10.1021/jp201543t.

[30] I. Bérend, J.-M. Cases, M. François, J.-P. Uriot, L. Michot, A. Masion, F. Thomas, Mechanism of Adsorption and Desorption of Water Vapor by Homoionic Montmorillonites: 2. The Li+ Na+, K+, Rb+ and Cs+-Exchanged Forms, Clays and Clay Minerals 43(3) (1995) 324336. https://doi.org/10.1346/ccmn.1995.0430307.

[31] S. Plimpton, Fast Parallel Algorithms for Short-Range Molecular Dynamics, Journal of Computational Physics 117(1) (1995) 1-19. https://doi.org/10.1006/jcph.1995.1039.

[32] P.H. Axelsen, M.J. Citra, Orientational order determination by internal reflection infrared spectroscopy, Progress in Biophysics and Molecular Biology 66(3) (1996) 227-253. https://doi.org/10.1016/S0079-6107(97)00007-2.

[33] K. Ohta, H. Ishida, Matrix formalism for calculation of electric field intensity of light in stratified multilayered films, Appl. Opt. 29(13) (1990) 1952-1959. https://doi.org/10.1364/ao.29.001952.

[34] K. Ohta, H. Ishida, Matrix formalism for calculation of the light beam intensity in stratified multilayered films, and its use in the analysis of emission spectra, Appl. Opt. 29(16) (1990) 2466-2473. https://doi.org/10.1364/ao.29.002466.

[35] N.J. Harrick, Electric Field Strengths at Totally Reflecting Interfaces, J. Opt. Soc. Am. 55(7) (1965) 851-857. https://doi.org/10.1364/josa.55.000851.

[36] N.J. Harrick, F.K. du Pré, Effective Thickness of Bulk Materials and of Thin Films for Internal Reflection Spectroscopy, Appl. Opt. 5(11) (1966) 1739-1743. https://doi.org/10.1364/ao.5.001739.

[37] A. Bagchi, R.G. Barrera, A.K. Rajagopal, Perturbative approach to the calculation of the electric field near a metal surface, Physical Review B 20(12) (1979) 4824-4838. https://doi.org/10.1103/PhysRevB.20.4824.

[38] J.E. Sipe, Bulk-selvedge coupling theory for the optical properties of surfaces, Physical Review B 22(4) (1980) 1589-1599. https://doi.org/10.1103/PhysRevB.22.1589.

[39] P.J. Feibelman, Surface electromagnetic fields, Progress in Surface Science 12(4) (1982) 287-407. https://doi.org/10.1016/0079-6816(82)90001-6.

[40] T. Higashiyama, T. Takenaka, Infrared attenuated total reflection spectra of adsorbed layers at the interface between a germanium electrode and an aqueous solution of sodium laurate, The Journal of Physical Chemistry 78(9) (1974) 941-947. https://doi.org/10.1021/j100602a016.

[41] F. Takeda, M. Matsumoto, T. Takenaka, Y. Fujiyoshi, Studies of poly- $\gamma$-methyl-1glutamate monolayers by infrared ATR and transmission spectroscopy and electron microscopy, Journal of Colloid and Interface Science 84(1) (1981) 220-227. https://doi.org/10.1016/0021-9797(81)90278-2. 
[42] W.-H. Jang, J.D. Miller, Molecular Orientation of Langmuir-Blodgett and Self-Assembled Monolayers of Stearate Species at a Fluorite Surface As Described by Linear Dichroism

684 Theory, The Journal of Physical Chemistry 99(25) (1995) 10272-10279. https://doi.org/10.1021/j100025a031.

[43] T. Buffeteau, M. Pézolet, Linear Dichroism in Infrared Spectroscopy, in: J.M. Chalmers, P.R. Griffiths (Eds.), Handbook of Vibrational Spectroscopy2001. https://doi.org/10.1002/0470027320.s0501.

[44] F. Picard, T. Buffeteau, B. Desbat, M. Auger, M. Pézolet, Quantitative orientation measurements in thin lipid films by attenuated total reflection infrared spectroscopy, Biophysical Journal 76(1) (1999) 539-551. https://doi.org/10.1016/s0006-3495(99)77222-x. [45] M.J. Citra, P.H. Axelsen, Determination of molecular order in supported lipid membranes by internal reflection Fourier transform infrared spectroscopy, Biophysical Journal 71(4) (1996) 1796-1805. https://doi.org/10.1016/s0006-3495(96)79380-3.

[46] T. Easwarakhanthan, S. Ravelet, P. Renard, An ellipsometric procedure for the characterization of very thin surface films on absorbing substrates, Applied Surface Science 90(2) (1995) 251-259. https://doi.org/10.1016/0169-4332(95)00084-4.

[47] W.J. Anderson, W.N. Hansen, Optical characterization of thin films*, J. Opt. Soc. Am. 67(8) (1977) 1051-1058. https://doi.org/10.1364/josa.67.001051.

[48] R.H.A. Ras, Y. Umemura, C.T. Johnston, A. Yamagishi, R.A. Schoonheydt, Ultrathin hybrid films of clay minerals, Physical Chemistry Chemical Physics 9(8) (2007) 918-932. https://doi.org/10.1039/b610698f.

[49] R.T. Cygan, J.-J. Liang, A.G. Kalinichev, Molecular Models of Hydroxide, Oxyhydroxide, and Clay Phases and the Development of a General Force Field, The Journal of Physical Chemistry B 108(4) (2004) 1255-1266. https://doi.org/10.1021/jp0363287.

[50] J.P. Larentzos, J.A. Greathouse, R. Cygan, An ab Initio and Classical Molecular Dynamics Investigation of the Structural and Vibrational Properties of Talc and Pyrophyllite, The Journal of Physical Chemistry C 111(34) (2007) 12752-12759. https://doi.org/10.1021/jp072959f.

[51] R.T. Cygan, J.A. Greathouse, H. Heinz, A.G. Kalinichev, Molecular models and simulations of layered materials, J. Mater. Chem. 19(17) (2009) 2470. https://doi.org/10.1039/b819076c.

[52] G.W. Brindley, G. Brown, M. Society, Crystal Structures of Clay Minerals and Their Xray Identification, Mineralogical Society1980. https://doi.org/10.1180/mono-5.

[53] R. Fraser, T. MacRae, Conformation in fibrous proteins and related synthetic polypeptides, Academic Press, New York, 1973. https://doi.org/10.1016/B978-0-12-266850-0.X5001-X.

[54] L. Pauling, E.B. Wilson, Introduction to Quantum Mechanics with Applications to Chemistry, Dover Publications2012. https://doi.org/10.1038/136972a0.

[55] C.T. Johnston, G.S. Premachandra, Polarized ATR-FTIR Study of Smectite in Aqueous Suspension, Langmuir 17(12) (2001) 3712-3718. https://doi.org/10.1021/la010184a.

[56] J.L. Suter, P.V. Coveney, H.C. Greenwell, M.-A. Thyveetil, Large-Scale Molecular Dynamics Study of Montmorillonite Clay: Emergence of Undulatory Fluctuations and Determination of Material Properties, The Journal of Physical Chemistry C 111(23) (2007) 8248-8259. https://doi.org/10.1021/jp070294b.

[57] M.-A. Thyveetil, P.V. Coveney, J.L. Suter, H.C. Greenwell, Emergence of undulations and determination of materials properties in large-scale molecular dynamics simulation of layered 
double hydroxides Chem. Mater.

$19(23)$

(2007)

$5510-5523$.

727 https://doi.org/10.1021/cm070923u.

728 [58] B. Carrier, M. Vandamme, R.J.M. Pellenq, M. Bornert, E. Ferrage, F. Hubert, H. Van

729 Damme, Effect of Water on Elastic and Creep Properties of Self-Standing Clay Films,

730 Langmuir 32(5) (2016) 1370-1379. https://doi.org/10.1021/acs.langmuir.5b03431.

731 [59] J.M. Cases, I. Berend, G. Besson, M. Francois, J.P. Uriot, F. Thomas, J.E. Poirier, 732 Mechanism of adsorption and desorption of water vapor by homoionic montmorillonite. 1 . The sodium-exchanged form, https://doi.org/10.1021/la00047a025.

Langmuir $\quad 8(11)$

(1992) 2730-2739. [60] M. Szczerba, A. Kuligiewicz, A. Derkowski, V. Gionis, G.D. Chryssikos, A.G. Kalinichev, Structure and Dynamics of Water-Smectite Interfaces: Hydrogen Bonding and the Origin of the Sharp O-D $\mathrm{D}_{\mathrm{W}} / \mathrm{O}-\mathrm{H}_{\mathrm{W}}$ Infrared Band From Molecular Simulations, Clays and Clay Minerals 64(4) (2016) 452-471. https://doi.org/10.1346/ccmn.2016.0640409.

[61] R.H.A. Ras, J. Németh, C.T. Johnston, I. Dékány, R.A. Schoonheydt, Orientation and conformation of octadecyl rhodamine B in hybrid Langmuir-Blodgett monolayers containing clay minerals, Physical Chemistry Chemical Physics 6(23) (2004) 5347-5352. https://doi.org/10.1039/b411339j.

[62] T. Dabat, F. Hubert, E. Paineau, P. Launois, C. Laforest, B. Grégoire, B. Dazas, E. Tertre, A. Delville, E. Ferrage, A general orientation distribution function for clay-rich media, Nature Communications 10(1) (2019) 5456. 10.1038/s41467-019-13401-0.

[63] P. Podsiadlo, A.K. Kaushik, E.M. Arruda, A.M. Waas, B.S. Shim, J. Xu, H. Nandivada, B.G. Pumplin, J. Lahann, A. Ramamoorthy, N.A. Kotov, Ultrastrong and Stiff Layered Polymer Nanocomposites, Science 318(5847) (2007) 80-83. https://doi.org/10.1126/science.1143176. [64] C. Aulin, G. Salazar-Alvarez, T. Lindström, High strength, flexible and transparent nanofibrillated cellulose-nanoclay biohybrid films with tunable oxygen and water vapor permeability, Nanoscale 4(20) (2012) 6622-6628. https://doi.org/10.1039/c2nr31726e.

[65] X.-F. Pan, H.-L. Gao, Y. Lu, C.-Y. Wu, Y.-D. Wu, X.-Y. Wang, Z.-Q. Pan, L. Dong, Y.H. Song, H.-P. Cong, S.-H. Yu, Transforming ground mica into high-performance biomimetic polymeric mica film, Nature Communications 9(1) (2018) 2974. https://doi.org/10.1038/s41467-018-05355-6.

[66] Q. Wang, J.L. Mynar, M. Yoshida, E. Lee, M. Lee, K. Okuro, K. Kinbara, T. Aida, Highwater-content mouldable hydrogels by mixing clay and a dendritic molecular binder, Nature

758 463(7279) (2010) 339-343. https://doi.org/10.1038/nature08693. 